\title{
The impact of COVID-19 on emergency surgical presentations in a university teaching hospital
}

\author{
Ahmed M. Kamil ${ }^{1} \cdot$ Matthew G. Davey ${ }^{1,2}$ (D) Fadi Marzouk $^{1} \cdot$ Rish Sehgal $^{1} \cdot$ Amy L. Fowler $^{1} \cdot$ Kevin Corless $^{1}$. \\ Maeve O'Neill' $^{1}$. Chris G. Collins ${ }^{1,2}$
}

Received: 11 June 2021 / Accepted: 29 June 2021 / Published online: 12 July 2021

(c) The Author(s) 2021

\begin{abstract}
Introduction The Coronavirus-19 (COVID-19) pandemic has led to a 50-70\% reduction in acute non-COVID-19 presentations to emergency departments globally.

Aim To determine the impact of COVID-19 on incidence, severity, and outcomes of acute surgical admissions in an Irish University teaching hospital.

Methods Descriptive data concerning patients presenting with acute appendicitis, diverticulitis, and cholecystitis were analysed and compared from March-May 2020 to March-May 2019.

Results Acute surgical admissions decreased in March from 191 (2020) to 55 (2019) (55\%), before increasing by 28\% in April (2019: 119, 2020: 153). Admissions due to acute cholecystitis reduced by 33\% (2019: 33, 2020: 22), with increased severity at presentation $(P=0.079)$ and higher 30 -day readmission rates $(P=0.056)$ reported. Acute appendicitis presentations decreased by $44 \%$ (2019: 78, 2020: 43, $P=0.019)$, with an increase in severity $(P<0.001)$, conservative management $(P<0.001)$, and post-operative complications $(P=0.029)$ in 2020 compared to the same period in 2019.

Conclusion COVID-19 has potentiated a significant reduction in acute surgical presentations to our hospital. Patients presenting with acute appendicitis during the pandemic had more severe disease, were more likely to have complications, and were significantly more likely to be managed conservatively when compared to historical data.
\end{abstract}

Keywords COVID-19 $\cdot$ Emergency surgery $\cdot$ Patient outcomes $\cdot$ Surgery

\section{Introduction}

In December 2019, an increase in the number of cases of viral pneumonia complicated with acute respiratory distress syndrome was observed in Wuhan, China. The Severe Acute Respiratory Syndrome Coronavirus (SARS-CoV-2 or COVID-19) viral infection spread exponentially worldwide, leading to an international public health emergency. [1].

In the forewarned countries of the western world, patients initially avoided presenting to hospitals due to fear of COVID-19 and its devastating effects [2]. Consequentially, global data depicted reduced numbers of people seeking

Matthew G. Davey

m.davey7@nuigalway.ie

1 Department of Surgery, Galway University Hospitals, Galway, Republic of Ireland

2 Department of Academic Surgery, National University of Ireland, Galway, Republic of Ireland medical advice for acute conditions and illness, and a delay in presentations [3-6]. The shift in this clinical paradigm has had significant effects on patient outcomes worldwide, as is evident in data published in several international studies. A large European series from Spain detailed a 40\% reduction in catheterisations being performed for ST-elevation myocardial infarction across 81 institutions, while another series recorded a $20 \%$ decrease in presentations with myocardial infarction in centres in the USA [2,5]. Other authors describe a series including 12 delayed acute paediatric presentations due to COVID-19 across five Italian hospitals in Northern Italy. They observed six children requiring urgent intensive care admissions, four of whom suffered mortality as a consequence [4]. Furthermore, there have been reports of a four-fold increase in time to first contact with medical professionals in Queen Mary Hospital, Hong Kong, since the outbreak of the pandemic [6].

These studies highlight the implications that COVID-19 has had on emergency services worldwide; however, there 
is limited data focusing on COVID-19 and acute emergency surgical presentations. The aim of the current study was to quantitatively analyse differences in presentation, management, and outcomes of common acute surgical conditions during the COVID-19 pandemic, compared with historical data one year previously.

\section{Methods}

Local ethical approval was obtained from the clinical ethical research council (Ref: C.A 2449). A retrospective cohort study was conducted at a tertiary referral hospital (Galway University Hospital, Ireland) between 1 March and 31 May 2020 and compared to the same time period 1 year previously (1 March to 31 May 2019). Patients presenting with acute appendicitis, acute diverticulitis, and cholecystitis were the main focus of the study.

Clinical, laboratory, and radiologic data concerning these presentations were collected using Emergency Department (ED) and Acute Surgical Assessment Unit (ASAU) logbooks, paper and electronic chart review, hospital electronic patient enquiry software, and electronic discharge summary. Inclusion criteria were all patients admitted acutely under a general surgical team with (1) acute appendicitis, (2) acute diverticular disease, or (3) acute gallbladder pathology (acute cholecystitis including cholangitis) within the specified time periods above. Data points collected include patients demographics, duration of symptoms, surgical pathology type, treatment method (surgical vs conservative), post-operative complications (Clavien-Dindo classification) [7], total length of hospital stay (LOS), 30-day readmission rate, and reason for readmission. Moreover, failure of conservative management was recorded, defined as no clinical improvement, and/or deterioration at $48 \mathrm{~h}$ from admission.

The simplified acute physiology score (SAPS-II) was used for all patients in the study to compare overall severity at presentation [8]. Tokyo Guidelines 18/13 system was used to assess severity of disease in gallbladder pathology [9]. For patients with acute appendicitis, two different scoring systems were used: the radiological appendicitis severity index (APSI), based on radiological assessment of appendicitis, as well as the disease severity score system (DSS) which assessed disease severity based upon histology and intraoperative findings [10, 11]. The Hinchey classification system was used for categorizing the severity of illness in the diverticulitis group [12].

All data were analysed using descriptive and inferrential statistics; Fishers exact, Chi-Squared, independent Student's $t$, and one-way analysis of variance (ANOVA) tests were used as appropriate. All tests of significance were 2-tailed, with $P<0.05$ indicating statistical significance. Data was analysed using Statistical Package for Social Sciences ${ }^{\mathrm{TM}}$ (SPSS ${ }^{\mathrm{TM}}$ ) version 26.0.

\section{Results}

\section{Clinical characteristics}

Eight hundred and fifty nine patients presented with an acute surgical emergency during the course of this study. There was a $10.4 \%$ decrease in acute surgical presentations overall (453 in 2019 versus 406 in 2020). One hundred and thirty-eight patients had one of the pre-defined acute surgical emergencies for inclusion in this study in 2019 (30.4\%), and 94 in $2020(23.1 \%)$. The mean age of patients presenting in 2019 was 41.2 years ( \pm 21.7 years), versus 46.7 years $( \pm 21.5$ years $)$ in $2020(P=0.034)$. Male to female ratio in 2019 was $0.64: 1$ (38.4\% to $61.5 \%)$, vs. $0.69: 1$ ( $41.4 \%$ to $58.5 \%)$ in $2020(P=0.335)$ (Table 1$)$.

\section{Patterns of emergency surgical presentations}

There was a 54.6\% decrease in acute surgical admissions in March 2020 versus March 2019 (194 admissions in 2019 vs. 88 in 2020). A $22.2 \%$ increase in acute surgical admissions was observed between April 2020 vs. April 2019 (153 admissions in 2019 vs. 119 in 2020) $(P=0.748)$ (Table 2), as well as $17.9 \%$ increase in surgical admissions between

Table 1 Demographics for acute emergency surgical presentations in March, April, and May 2019 versus the same time period in 2020

\begin{tabular}{lll}
\hline Demographics & 2020 & 2019 \\
\hline $\begin{array}{l}\text { Total number of surgical admissions to } \\
\text { GUH (Mar-May) }\end{array}$ & 406 & 453 \\
March & $88(21.6 \%)$ & $194(42.8 \%)$ \\
April & $153(37.6 \%)$ & $119(26.2 \%)$ \\
May & $165(40.6 \%)$ & $140(30.9 \%)$ \\
Number of patients included in the study & $94(23.1 \%)$ & $138(30.4 \%)$ \\
Mean age \pm SD (years) & $41( \pm 21.7)$ & $47( \pm 21.5)$ \\
Gender & & \\
Male & $39(41.4 \%)$ & $53(38.4 \%)$ \\
Female & $55(58.5 \%)$ & $85(61.5 \%)$ \\
Presentation by month (Total numbers) & 94 & 138 \\
$\quad$ March & $30(31.9 \%)$ & $50(36.2 \%)$ \\
April & $30(31.9 \%)$ & $39(28.2 \%)$ \\
$\quad$ May & $34(36.1 \%)$ & $49(35.5)$ \\
Presentation by specific pathology & & \\
$\quad$ Acute cholecystitis & 22 & 33 \\
Acute appendicitis & 43 & 78 \\
Acute Diverticulitis & 29 & 27 \\
\hline
\end{tabular}

GUH Galway University Hospitals, Mar March, SD standard deviation 
Table 2 Cohort group presentation by month

\begin{tabular}{lll}
\hline Presentations & 2020 & 2019 \\
\hline Cholecystitis & & \\
Total & 22 & 33 \\
$\quad$ March & $4(18.1 \%)$ & $15(45.4 \%)$ \\
$\quad$ April & $10(45.4 \%)$ & $11(33.3 \%)$ \\
$\quad$ May & $8(36.3 \%)$ & $7(21.2 \%)$ \\
Appendicitis & & \\
Total & 43 & 78 \\
$\quad$ March & $17(39.5 \%)$ & $26(33.3 \%)$ \\
$\quad$ April & $12(27.9 \%)$ & $21(26.9 \%)$ \\
$\quad$ May & $14(32.5 \%)$ & $31(39.7 \%)$ \\
Diverticulitis & & 27 \\
Total & 29 & $9(33.3 \%)$ \\
$\quad$ March & $9(31.0 \%)$ & $7(25.9 \%)$ \\
April & $8(27.5 \%)$ & $11(40.7 \%)$ \\
$\quad$ May & $12(41.3 \%)$ &
\end{tabular}

May 2019 and May 2020 (140 admissions in May 2019 vs. 165 in May 2020).

In the cholecystitis group, 15 patients presented with acute symptoms in March 2019, versus 4 patients in 2020, a decrease of $73.3 \%$. This was followed by no reduction in April and May. In the appendicitis group, a significant reduction in acute presentations was observed between 2020 and 2019 for all months $(34.6 \%, 42.8 \%$, and $54.8 \%$ reductions for March, April, and May, respectively). In the diverticulitis group, similar number of presentations recorded in the 2 years with no significant difference throughout the study period (Table 2; Fig. 1).

\section{Duration of symptoms}

The mean duration of symptoms prior to presenting to emergency surgical services was $2.70( \pm 2.86)$ days in 2019 versus $3.13( \pm 2.67)$ days in $2020(P=0.244)$. Subgroup analysis of the duration of symptoms for the three

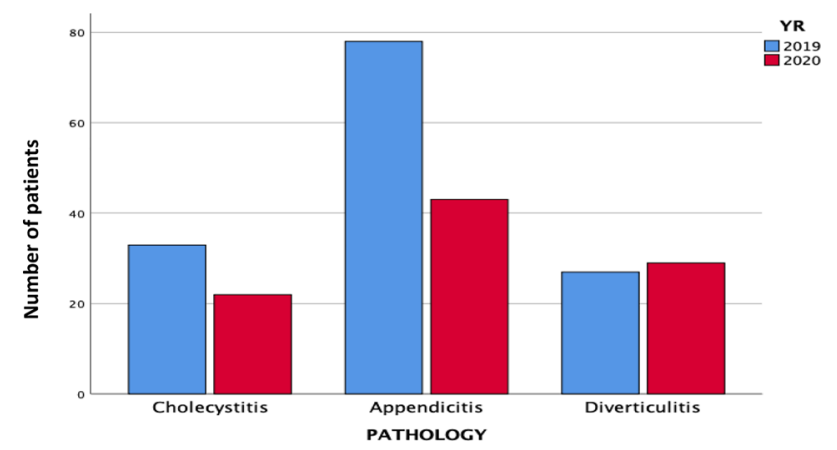

Figure. 1 Pathology subgroup difference in presentations between 2020 and 2019
Table 3 Duration of symptoms

\begin{tabular}{llll}
\hline Year & 2020 & 2019 & $P$-value \\
\hline Duration of symptoms (days) & & & \\
$\quad$ Cholecystitis & 3.54 & 3.57 & 0.975 \\
$\quad$ Appendicitis & 2.4 & 1.8 & 0.067 \\
$\quad$ Diverticulitis & 3.7 & 4.1 & 0.708 \\
Mean duration of symptoms & $3.13 \pm 2.67$ & $2.70 \pm 2.86$ & 0.244 \\
\hline
\end{tabular}

groups demonstrated no statistical significance. The largest difference was seen in the appendicitis group $(P=0.067)$, while the remaining two groups showed a similar pattern in both years (Table 3 ).

\section{Treatment}

Fewer acute surgical procedures were performed in 2020 versus 2019 . In $2019,60.9 \%$ of patients admitted with acute surgical emergencies underwent surgical intervention (84/138), while $39.1 \%$ were treated conservatively (54/138) (Fig. 2). In 2020, 35.1\% of admissions underwent surgical intervention $(33 / 94)$, while $64.9 \%$ were treated conservatively $(P<0.001)$. The number of patients with operative management of acute appendicitis was lower in 2020 (29/43, 67.4\%), compared to 2019 (77/78, 98.7\%) (Fig. 3). Of the 20 patients initially treated conservatively for acute appendicitis (46.5\%), 5 failed conservative management and proceeded to surgery $(25 \%)(P<0.001)$, while another patient represented within 30 days with recurrence of symptoms and underwent appendicectomy. Cross-sectional imaging (CT abdomen and pelvis) was utilised to aid diagnosis in 26 patients with appendicitis in $2020(26 / 43,60.4 \%)$ versus 13 in $2019(13 / 78,17.1 \%)$ $(P=0.001)$. One patient had a normal appendiceal histology following surgery in 2020 versus 7 in 2019 (1/43 vs. $7 / 78 P=0.350)$ (Table 4).

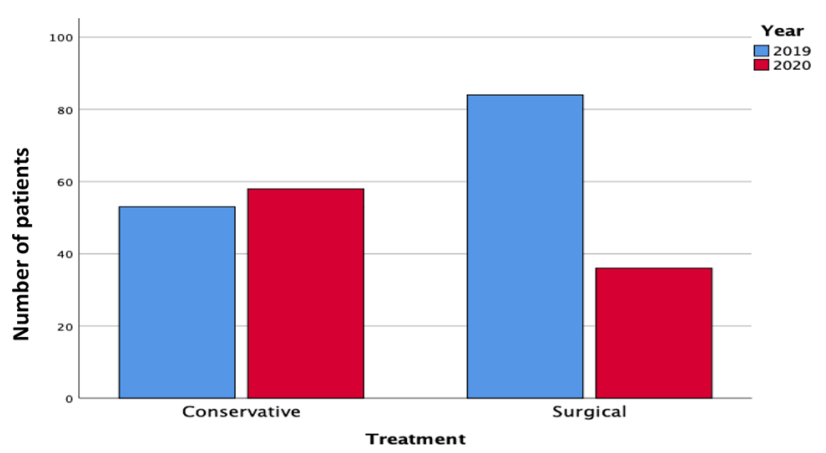

Figure. 2 Overall treatment method adopted between 2020 and 201 
Table 4 Breakdown of treatment method (conservative vs surgical)

\begin{tabular}{llll}
\hline Treatment & 2020 & 2019 & $P$-value \\
\hline Total number of cases & 94 & 138 & \\
$\quad$ Surgical & $33(35.1 \%)$ & $84(60.8 \%)$ & $<0.001^{*}$ \\
Conservative & $61(64.8 \%)$ & $54(39.1 \%)$ & \\
Cholecystitis & $N=22$ & $N=33$ & \\
$\quad$ Surgical & 1 & 4 & 0.378 \\
Conservative & 21 & 29 & \\
Appendicitis & $N=43$ & $N=78$ & $<0.001^{*}$ \\
$\quad$ Surgical & 29 & 77 & \\
$\quad$ Conservative & 14 & 1 & 0.927 \\
Diverticulitis & $N=29$ & $N=27$ & \\
$\quad$ Surgical & 3 & 3 & \\
Conservative & 26 & 24 & \\
\hline
\end{tabular}

$N$ number

*Statistical significance

\section{Morbidity and mortality}

No major post-operative complications were recorded in either year of this study period for patients who underwent operative management of appendicitis, diverticulitis, or cholecystitis. In 2019, 77 patients with acute appendicitis were treated surgically $(98.7 \%)$, vs. 29 in 2020 (67.4\%). Of the 77 patients in $2019,5(6.5 \%)$ subsequently developed a post-operative complication, as did 7 of those treated in 2020 (24.1\%) $(P=0.029)$. The incidence of post-operative complications was similar across both years for patients receiving surgical intervention for acute cholecystitis $(P=0.378)$. One patient died during this study (Table 5).

Table 5 Disease specific post-operative complications and mortality

\begin{tabular}{clll}
\hline & 2020 & 2019 & $P$-value \\
\hline Cholecystitis & $N=1$ & $N=4$ & \\
None & 0 & 0 & \\
CD1 & 0 & 1 & $P=0.378$ \\
CD2 & 1 & 3 & \\
Mortality & 0 & 1 & \\
Appendicitis & $N=29$ & $N=76$ & \\
None & 22 & 71 & \\
CD1 & 4 & 3 & \\
CD2 & 3 & 2 & \\
Diverticulitis & $N=3$ & $N=3$ & \\
None & 0 & 3 & \\
CD1 & 0 & 0 & \\
CD2 & 1 & 0 & \\
\hline
\end{tabular}

$C D$ Clavien-Dindo morbidity scale, $N$ number

*Statistical significance

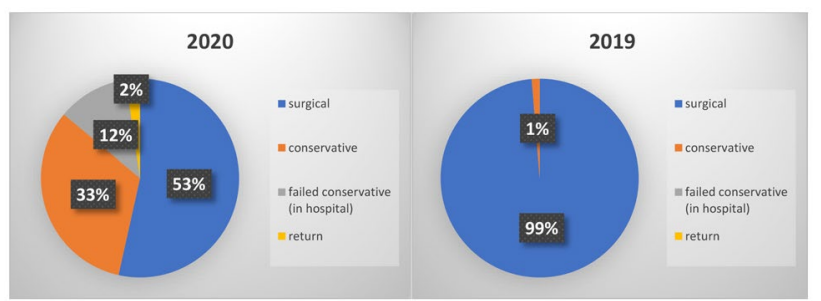

Figure. 3 Management of acute presentations with appendicitis induring the study period

\section{Length of hospital stay}

There was an overall reduction in LOS from 2019 to 2020 (2019: 4.7 days vs. 2020: 4.3 day, $P=0.267$ ). Median LOS was increased for patients with acute cholecystitis in 2020 compared to 2019 (6.5 days vs. 4 days, $P=0.606$ ), and similarly was prolonged for patients admitted with appendicitis (2019: 2 days vs. 2020: 3 Days, $P=0.045$ ). Decreased LOS was observed for patients with diverticulitis (2019: 4 days vs. 2020: 3 days) $(P=0.002)$ (Table 6).

\section{Readmissions}

There was an overall increase in readmission rates in 2020 versus $2019(11 / 94 v s .7 / 138, P=0.166)$. One patient from the cholecystitis group was readmitted within 30 days of discharge in 2019 (1/33), compared to 4 in 2020 (4/22, $P=0.056)$. Six patients with appendicitis were readmitted in $2019(6 / 78)$ versus seven in $2020(7 / 43, P=0.326)$. There were no readmissions recorded for patients with diverticulitis in either year (Table 7).

\section{Severity of symptoms and disease}

The mean SAPS-II score of $13.92 \pm 7.38$ was recorded in 2019 , compared to $16.25 \pm 8.03$ in $2020(P=0.031)$. Following subgroup analysis of SAPS-II score, an upward trend was noticed in all groups. The largest increase occurred in the cholecystitis group (2019: $20.0 \pm 11.16$ vs. 2020: $23.5 \pm 10.2$, $P=0.246)$, with the least in the appendicitis group (2019: $10.03 \pm 4.04$ vs. $2020: 10.5 \pm 3.14, P=0.487$ ) (Table 8).

Table 6 Total length of hospital-stay

\begin{tabular}{llll}
\hline & 2020 & 2019 & $P$-value \\
\hline Median LOS (days) & & & \\
Cholecystitis & $6.5(0-25)$ & $4(0-60)$ & 0.606 \\
Appendicitis & $3(1-10)$ & $2(1-13)$ & $0.045^{*}$ \\
Diverticulitis & $3(0-14)$ & $4(2-18)$ & $0.002^{*}$ \\
Overall mean LOS & 4.3 & 4.7 & 0.267 \\
\hline
\end{tabular}

LOS length of hospital stay

*Statistical significance 
Table 7 Thirty-day readmission rates for patients discharged with acute cholecystitis, appendicitis, and diverticulitis

\begin{tabular}{llll}
\hline Readmissions & 2020 & 2019 & $P$-value \\
\hline Overall & $11 / 94$ & $7 / 138$ & 0.166 \\
Cholecystitis & $4 / 22$ & $1 / 33$ & 0.056 \\
Appendicitis & $7 / 43$ & $6 / 78$ & 0.194 \\
Diverticulitis & $0 / 29$ & $0 / 27$ & N/R \\
\hline
\end{tabular}

$N / R$ not recordable

An increase in disease severity was noted among patients presenting with cholecystitis in 2020 , with a mean severity grade of 1.6 in 2019 compared to 2.0 in 2020, based on the Tokyo Guidelines classification $(P=0.079)$ (Table 9). There was an increase in the number of patients presenting with severe acute cholecystitis, with 7/22 (31.8\%) presenting with grade 3 disease compared to $3 / 33$ patients in 2019 (9.0\%, $P=0.043)$. For patients with acute appendicitis, the mean APSI score was $4.5( \pm 3.33)$ in $2020 v s .2 .1( \pm 1.16)$ in 2019 $(P<0.001)$ (Table 9). In 2020, the mean DSS score was 1.75 $( \pm 1.214)$ vs. $1.35( \pm 0.817)$ in $2019(P=0.003)$ (Table 9). For patients with diverticulitis, similar grades of disease were observed each year using the Hinchey classification system to stratify disease severity $(P=0.930)$ (Table 9$)$.

\section{Discussion}

The outbreak of the COVID-19 pandemic has forced healthcare systems across the globe to adapt practices, allocate scarce resources, and tailor management strategies in order to optimize patient care. Our understanding of COVID-19 and the threat posed by novel variants remains uncertain, and there is currently a paucity of evidence pertaining to the pathophysiological, natural history, and molecular pathways of COVID-19, with surgical guidelines and management protocols relating to COVID-19 continuing to evolve rapidly. Therefore, the aim of the present study was to quantitatively analyse differences in presentation, management, and outcomes of acute surgical conditions during the initial months of the COVID-19 pandemic compared with the previous year. The most significant finding in this analysis of

Table 8 Overall severity index at presentation by SAPS-II

\begin{tabular}{llll}
\hline Mean SPAS-II & 2020 & 2019 & $P$-value \\
\hline Cholecystitis & $23.5($ Std. 10.2) & $20.0($ Std. 11.16) & 0.246 \\
Appendicitis & $10.5($ Std 3.14) & $10.03($ Std 4.04) & 0.487 \\
Diverticulitis & $19.2($ Std. 6.19) & $17.6($ Std 3.37) & 0.258 \\
Overall & $16.25($ Std 8.03) & $13.92(7.38)$ & 0.031 \\
\hline
\end{tabular}

SPAS-11 Simplified Acute Physiology Score II, std standard deviation
Table 9 Disease specific severity score

\begin{tabular}{clll}
\hline & 2020 & 2019 & $P$ value \\
\hline TG18/13 & $(N=22)$ & $(N=33)$ & \\
G1 & 8 & 15 & \\
G2 & 6 & 15 & 0.079 \\
G3 & 7 & 3 & \\
Mean & 2.0 & 1.6 & \\
APSI & $(N=26)$ & $(N=13)$ & \\
0 & 1 & 1 & \\
1 & 10 & 3 & \\
2 & 5 & 2 & \\
3 & 5 & 4 & 0.001 \\
4 & 5 & 2 & \\
5 & 1 & 1 & \\
Mean & $4.5($ Std. 3.33) & $2.1($ Std 1.16) & \\
DSS & $N=29$ & $N=77$ & \\
Mean & 1.75 (Std 1.214) & $1.35($ Std 0.817$)$ & \\
Hinchey & $N=29$ & $N=27$ & \\
1 & 23 & 18 & \\
2 & 6 & 9 & 0.930 \\
3 & 0 & & \\
\hline
\end{tabular}

$N$ number, $T G$ Tokyo Guidelines $18 / 13, G$ grade, APSI radiological appendicitis severity index, Std standard deviation, DSS disease severity score

almost 900 acute surgical presentations was the decline in presentations to the emergency department with acute surgical pathology, as well as the increased severity of symptomology during the COVID-19 pandemic.

These results reflect an extremely worrying trend hypothesised by expert consultant surgeons worldwide; during the initial phase of the COVID-19 pandemic, symptomatic patients requiring emergency surgical admission elected to isolate and suffer at home, instead of presenting to hospital, given the potential implications of COVID-19. This hypothesis is supported by the data captured in this study, with an overall declining trend in acute surgical presentations of $31.8 \%$, including a staggering $54.6 \%$ decline during March. Furthermore, patients presented with more severe subjective symptomology, and had increased hospital LOS. A similar trend was observed during the SARS pandemic, when a Taiwanese study demonstrated widespread patient reluctance to attend medical services, due to a perceived risk of viral transmission and infection [13]. Moreover, the Orsola-Malpighi University Hospital in Bologna, Italy, have reported a greater than $70 \%$ decrease in ocular emergency presentations during COVID-19 [3], while large pooled data from 47 American states outline a $20 \%$ reduction in acute stroke presentations as well as a $10 \%$ decrease in hyperglycaemic crisis during the initial phase of the COVID-19 pandemic [2]. 
Associated with the reduced number of presentations, increased severity of disease, and overall increased LOS, patients also reported experiencing symptoms for a longer duration prior to presenting to hospital; the mean duration of symptoms was 2.70 days in 2019 vs. 3.13 days in 2020 . Once more, this illustrates a worrying trend affecting the delivery of care to surgical patients. This appears to be translatable to other medical specialties, as data presented by Queen Mary Hospital, Hong Kong, demonstrated a four-fold increase in the time between onset of symptoms in patients presenting with acute myocardial infarction to first medical contact [6]. An Italian study incorporating 5 paediatric hospitals over 1 week demonstrated 12 cases of delayed presentations, of which 6 required an immediate admission for intensive care, and mortality occurred in 4 children [4]. It is well established that for patients with acute surgical pathology requiring emergency surgery, the timing of presentation from initiation of symptoms is an important factor in determining disease severity and patient outcomes [14, 15]. Thus, the authors wish to reiterate the serious implications of delayed presentations on clinical outcomes for patients of all demographics and in various healthcare settings, and highlight the barrier presented by COVID-19 as physicians worldwide attempt to provide benchmark care.

Results from this analysis highlight excellent trueappendicitis rates during the COVID-era; surgeons correctly diagnosed appendicitis in $97.7 \%$ of cases in patients who had an appendicectomy in 2020, compared to in $91.0 \%$ of cases in 2019. The authors acknowledge that this statistic presents a mere consolation when we acknowledge the increased subjective symptomology, reduced number of presentations, and significant reduction in patients managed operatively for this acute pathology. Increased utilisation of CT imaging to aid clinical decision making is likely to have affected the overall success rate in acute appendicitis detection. In well-resourced healthcare systems, perhaps incorporation of stringent imaging modalities into acute surgical assessment pathways may reduce the overall occurrence of false appendicitis rates, which have reported to be has high as $20 \%$ in some series [16].

The current global pandemic has had a number of implications which continue to limit surgical practice. Staff redeployment, requirement to reserve hospitals beds for COVID positive patients, scarcity of personal protective equipment, risk of viral transmission among care givers, and uncertainty surrounding the impact of possible infection on patients post-operatively have all placed restraints on global surgery, as described by the COVIDSurg collaborative, among others [17-23]. Surgical services were necessitated to adapt their approach toward conservative measures where possible, as outlined in this analysis, with intervention limited to urgent time-sensitive malignancies and life-threatening emergency surgery in the setting of the critically unwell.
This study has obvious limitations, being a retrospective cohort study, conducted in a single centre. Details pertaining to clinical outcomes are limited as a consequence of this; however, remain pertinent in detailing how COVID-19 has impacted surgical services at our tertiary referral centre.

This study highlights the manner in which COVID-19 has reduced the number of acute emergency surgical presentations during the initial 3-month period of the pandemic, as patients present with subjectively severe symptoms following an initial delay. Patient education surrounding the serious nature and potentially catastrophic impact of acute surgical emergencies seems imperative, as we continuously adapt surgical practice in response to the many challenges which threaten the delivery of excellent patient care during the current global public health crisis.

Funding Open Access funding provided by the IReL Consortium

Disclosures This manuscript has been accepted for presentation at the Sylvester O'Halloran Perioperative Symposium, 4th March 2021, Limerick, Republic of Ireland. Otherwise, nothing to disclose.

Open Access This article is licensed under a Creative Commons Attribution 4.0 International License, which permits use, sharing, adaptation, distribution and reproduction in any medium or format, as long as you give appropriate credit to the original author(s) and the source, provide a link to the Creative Commons licence, and indicate if changes were made. The images or other third party material in this article are included in the article's Creative Commons licence, unless indicated otherwise in a credit line to the material. If material is not included in the article's Creative Commons licence and your intended use is not permitted by statutory regulation or exceeds the permitted use, you will need to obtain permission directly from the copyright holder. To view a copy of this licence, visit http://creativecommons.org/licenses/by/4.0/.

\section{References}

1. WHO (2020) Director-General's remarks at the media briefing on 2019-nCoV. Available from: http://www.who.int/dg/speeches/ detail/who-director-general-s-remarks-at-the-media-briefing-on2019-ncov-on-11-february-2020

2. Lange SJ, Ritchey MD, Goodman AB et al (2020) Potential indirect effects of the COVID-19 pandemic on use of emergency departments for acute life-threatening conditions-United States, JanuaryMay 2020. MMWR Morb Mortal Wkly Rep 69(25):795-800

3. Pellegrini M, Roda M, Lupardi E et al (2020) The impact of COVID-19 pandemic on ophthalmological emergency department visits. Acta Ophthalmol. https://doi.org/10.1111/aos.14489

4. Lazzerini M, Barbi E, Apicella A et al (2020) Delayed access or provision of care in Italy resulting from fear of COVID-19. Lancet Child Adolesc Health 4(5):e10-e11

5. Rodriguez-Leor O, Cid-Alvarez B (2020) ST-segment elevation myocardial infarction care during COVID-19: losing sight of the forest for the trees. JACC Case Rep 2(10):1625-1627

6. Tam CF, Cheung KS, Lam S et al (2020) Impact of Coronavirus Disease 2019 (COVID-19) outbreak on ST-segment-elevation myocardial infarction care in Hong Kong, China. Circ Cardiovasc Qual Outcomes. 13(4):e006631 
7. Dindo D, Demartines N, Clavien PA (2004) Classification of surgical complications: a new proposal with evaluation in a cohort of 6336 patients and results of a survey. Ann Surg 240(2):205-213

8. Le Gall JR, Lemeshow S, Saulnier F (1993) A new Simplified Acute Physiology Score (SAPS II) based on a European/North American multicenter study. Jama 270(24):2957-2963

9. Yokoe M, Hata J, Takada T et al (2018) Tokyo Guidelines 2018: diagnostic criteria and severity grading of acute cholecystitis (with videos). J Hepato-Biliary-Panc Sci 25(1):41-54

10. Avanesov M, Wiese NJ, Karul M et al (2018) Diagnostic prediction of complicated appendicitis by combined clinical and radiological appendicitis severity index (APSI). Eur Radiol 28(9):3601-3610

11. Garst GC, Moore EE, Banerjee MN et al (2013) Acute appendicitis: a disease severity score for the acute care surgeon. J Trauma Acute Care Surg 74(1):32-36

12. Klarenbeek BR, de Korte N, van der Peet DL, Cuesta MA (2012) Review of current classifications for diverticular disease and a translation into clinical practice. Int J Colorectal Dis 27(2):207-214

13. Chang HJ, Huang $\mathrm{N}$, Lee $\mathrm{CH}$ et al (2004) The impact of the SARS epidemic on the utilization of medical services: SARS and the fear of SARS. Am J Public Health 94(4):562-564

14. Ong M, Guang TY, Yang TK (2015) Impact of surgical delay on outcomes in elderly patients undergoing emergency surgery: a single center experience. World J Gastrointest Surg 7(9):208-213

15. Gerall CD, DeFazio JR, Kahan AM et al (2020) Delayed presentation and sub-optimal outcomes of pediatric patients with acute appendicitis during the COVID-19 pandemic. J Pediatr Surg

16. Graff L, Russell J, Seashore J et al (2000) False-negative and false-positive errors in abdominal pain evaluation: failure to diagnose acute appendicitis and unnecessary surgery. Acad Emerg Med 7(11):1244-1255

17. Moletta L, Pierobon ES, Capovilla G et al (2020) International guidelines and recommendations for surgery during Covid-19 pandemic: a Systematic Review. Int J Surg 79:180-188

18. Lei S, Jiang F, Su W et al (2020) Clinical characteristics and outcomes of patients undergoing surgeries during the incubation period of COVID-19 infection. E Clinical Med. 21:100331

19. Collaborative CO (2020) Mortality and pulmonary complications in patients undergoing surgery with perioperative SARS-CoV-2 infection: an international cohort study. Lancet 396(10243):27-38

20. De Simone B, Chouillard E, Di Saverio S et al (2020) Emergency surgery during the COVID-19 pandemic: what you need to know for practice. Ann R Coll Surg Engl 102(5):323-332

21. Johnson GK, Robinson WS (1991) Human immunodeficiency virus-1 (HIV-1) in the vapors of surgical power instruments. J Med Virol 33(1):47-50

22. Gloster HM Jr, Roenigk RK (1995) Risk of acquiring human papillomavirus from the plume produced by the carbon dioxide laser in the treatment of warts. J Am Acad Dermatol 32(3):436-441

23. Ranney ML, Griffeth V, Jha AK (2020) Critical supply shortagesthe need for ventilators and personal protective equipment during the Covid-19 pandemic. New England J Med. 382(18):e41

Publisher's Note Springer Nature remains neutral with regard to jurisdictional claims in published maps and institutional affiliations. 